\title{
Strategi Corporate Social Responsibility Dompet Dhuafa dalam Membangun Brand Differentiation Lembaga
}

\author{
Iswahyu Pranawukir ${ }^{*}$, Agus Hitopa Sukma2 \\ 1'Institut Bisnis dan Informatika Kosgoro 1957, Jakarta, Indonesia, email: prana1enator@gmail.com \\ 2Institut Bisnis dan Informatika Kosgoro 1957, Jakarta, Indonesia, email: agushitopa@gmail.com \\ *Koresponden Penulis
}

\section{Info Artikel}

Submit: 13 Okt 2020

Accepted: 16 Feb 2021

Publish: 24 Feb 2021

Keywords:

CSR; Brand Differentiation;

Dompet Dhuafa

Kata Kunci:

CSR; Brand Differentiation;

Dompet Dhuafa

\section{(cc) EY-SA}

Lisensi: cc-by-sa

\begin{abstract}
The research aims to determine the Dompet Dhuafa Foundation's CSR strategy in building brand differentiation through the establishment of the Smart Ekselensia Republika school. It also concerns the dynamics of the Dompet Dhuafa Foundation's business paradigm which focuses on CSR programs to form brand differentiation. This type of research is case study with a qualitative descriptive method. It aims to describe the establishment of a school accompanied by an explanation of the process of occurrence, development and changes in various aspects of the dynamics of its CSR. Thus, there are peculiarities of cases which the researcher describes descriptively based on dynamic and contextual chronology. The results showed that the Dompet Dhuafa Foundation's CSR strategy in building brand differentiation is based on social awareness, that business contributions are social benefits; economic awareness, that the maximum profit from business is the maximum benefit in increasing charity in society; and legal awareness, that justice efforts that have been criticized by the pudblic can be maximally fulfilled because the efforts being carried out have a segment of the dhuafa. Differentiation is an achievement that combines the shared value business context in the three intelligences. Intellectual intelligence is proven in the provision of education, emotional intelligence by building social service businesses for the poor, as well as spiritual intelligence with the principles of trust, worship and Islam. So, business differentiation is a business that presents God in its operations.
\end{abstract}
Abstrak
Tujuan penelitian untuk mengetahui strategi CSR Yayasan Dompet Dhuafa dalam membangun brand differentiation melalui pendirian sekolah Smart Ekselensia Republika. Hal itu juga menyangkut dinamika paradigmatis bisnis Yayasan Dompet Dhuafa yang memusatkan perhatian pada program CSR hingga membentuk brand differentiation. Jenis penelitian adalah studi kasus yang bersifat deskriptif kualitatif untuk menjabarkan pendirian sekolah disertai penjelasan proses terjadinya, perkembangan dan perubahan-perubahan berbagai aspek dinamika CSRnya. Dengan demikian, terdapat kekhasan kasus yang peneliti jabarkan secara deskriptif berdasarkan kronologi dinamis dan kontekstualnya. Hasil penelitian menunjukkan bahwa strategi CSR Yayasan Dompet Dhuafa dalam membangun brand differentiation didasari oleh kesadaran sosial, bahwa kontribusi bisnis adalah kemaslahatan sosial; kesadaran ekonomi, bahwa keuntungan maksimal bisnis adalah keuntungan maksimal dalam meningkatkan charity pada masyarakat; dan kesadaran hukum, bahwa usaha keadilan yang dijadikan kritik publik dapat dipenuhi secara 
maksimal karena usaha yang dilakukan memiliki segmen dhuafa. Differentiation merupakan pencapaian yang memadukan konteks bisnis nilai bersama dalam tiga kecerdasan. Kecerdasan intelektual dibuktikan dalam penyelenggaraan pendidikan, kecerdasan emosional dengan membangun usaha layanan sosial kaum dhuafa, serta kecerdasan spiritual dengan prinsip amanah, ibadah dan islamiah. Jadi diferensiasi bisnis merupakan bisnis yang menghadirkan Tuhan dalam operasionalnya.

\section{PENDAHULUAN}

Dalam konteks Indonesia, CSR telah dinyatakan dalam UU Perseroan Terbatas no. 40 Tahun 2007. Pasal 74 menyatakan bahwa: (1) Perseroan yang menjalankan kegiatan usahanya di bidang dan/atau berkaitan dengan sumberdaya alam wajib melaksanakan tanggung jawab sosial dan lingkungan. (2) Tanggung jawab sosial dan lingkungan merupakan kewajiban perseroan yang dianggarkan dan diperhitungkan sebagai biaya perseroan yang pelaksanaannya dilakukan dengan memperhatikan kepatutan dan kewajaran. (3) Perseroan yang tidak melaksanakan kewajiban dikenai sanksi sesuai dengan ketentuan peraturan perundang-undangan. (4) Ketentuan lebih lanjut mengenai tanggung jawab sosial dan lingkungan diatur dengan peraturan pemerintah (Dewi et al., 2020). Di lain pihak, urgensi CSR perlu dilandasi oleh kesadaran perusahaan terhadap fakta, yakni adanya jurang yang semakin menganga antara kemakmuran dan kemelaratan, baik pada tataran global maupun nasional. Oleh karena itu, diwajibkan atau tidak, CSR haruslah merupakan komitmen dan kepedulian dari pelaku bisnis untuk mengambil peran dalam mengurangi nestapa kemanusiaan (Erawaty, 2009).

Corporate Social Responsibility (CSR) banyak dipahami sebagai komponen sustainability (keberlanjutan) atau sustainable (dapat berlanjut), artinya CSR dibutuhkan sebagai bagian dari program bisnis sekaligus survival korporasi (Nayenggita et al., 2019). Pada konteks tersebut, CSR bukan lagi soal shares tapi needs. Bagi korporasi yang tingkat dananya besar untuk CSR akan dipandang "berbeda" oleh masyarakat, yang kemudian diyakini akan berdampak pada aspek simpatik terhadap komoditas yang dijual. Akibatnya, semakin besar lingkup pengelolaan CSR cenderung meningkatkan image sebuah korporasi. Argumentasi tersebut terus berkembang seiring dengan era, yang kini era marketing sudah berada pada wacana 3.0, yakni values driven marketing atau istilah mudahnya values oriented, dari sebelumnya product oriented dan customer oriented (Adiyanto \& Sunaryo, 2017). Jika dalam legacy marketing merk menjadi andalan, kini berubah menjadi differentiation. Differentiation kaitannya dengan CSR memiliki aspek sangat sinergis. Aspek inklusif akan menimbulkan dukungan sosial yang positif, karena karakter masyarakat sosial Indonesia yang menyukai keterbukaan. Sampai di sini tentunya dapat diafirmasikan bahwa untuk membangun brand differentiation dibutuhkan CSR. CSR bukan lagi problematika sosial ironis dari korporasi tetapi menjadi "strategi". Untuk mendapatkan dukungan shareholders dan stakeholders secara maksimal membutuhkan upaya yang tidak singkat.

Hingga kini hasil CSR berupa sekolah Smart Ekselensia itu cukup berhasil meluluskan generasi seperti idealisme Indonesia, yakni paralel antara iptek dan imtaq. Jika banyak juga yayasan philantrophy sejenis yang dianggap justru mengeksploitasi kemiskinan menjadi komoditas tetapi Dompet Dhuafa justru berhasil membangun brand differentiation itu. Program CSR yang dikerjakannya diterima oleh publik sebagai hal yang sangat positif, demikian pula oleh para korporasi yang berafiliasi di dalamnya. Semakin besar lingkup pengelolaan CSR akan meninggikan image.

CSR atau tanggung jawab sosial sebuah korporasi, atas tuntutan distribusi keuntungan tersebut, pada awalnya tentu disikapi beragam. Bisa saja sebagai peredam 
konflik dengan masyarakat sekitar sehingga CSR dilaksanakan dengan misi pemberian derma saja, atau memang ada panggilan jiwa dari pihak manajemen untuk menyalurkan sebagian keuntungannya atas motivasi emosional atau spiritual.

Di lain pihak tentu ada pula korporasi yang memang merasa bertanggung jawab akibat dampak dari industri yang dibangunnya dirasa merugikan masyarakat sekitar atau bahkan merusak lingkungan tempat tinggal. Sampai akhirnya kehadiran "media baru" mendorong korporasi untuk memaksimalkan segala potensi strategis yang dimiliki demi kelangsungan bisnis yang dijalaninya. Sampai disini CSR kemudian banyak dipahami sebagai komponen sustainability (keberlanjutan) atau sustainable (dapat berlanjut).

Pada konteks tersebut, maka CSR bukan lagi soal shares tapi needs. CSR dipandang berkontribusi terhadap awareness publik terhadap citra, reputasi, track record yang menyentuh pula aspek-aspek sustainability jangka pendek, menengah dan panjang dari operasionalisasi bisnis korporasi. Bagi korporasi yang tingkat dananya besar untuk CSR akan dipandang "berbeda" oleh masyarakat, yang kemudian diyakini akan berdampak pada aspek simpatik publik terhadap produk yang dijual. Akibatnya, semakin besar lingkup pengelolaan CSR sebuah korporasi tentu akan mengakibatkan image yang semakin tinggi dari sebuah korporasi (Aryawan et al., 2017).

Argumentasi tersebut terus berkembang seiring dengan era, yang kini era marketing sudah berada pada wacana 3.0, yakni values driven marketing atau istilah mudahnya values oriented, dari sebelumnya product oriented dan customer oriented. Jika dalam legacy marketing merk menjadi andalan, kini berubah menjadi differentiation.

Differentiation dalam kaitannya dengan CSR sangat sinergis. CSR sebagai program yang menyentuh langsung pada kebutuhan masyarakat sosial sangat inklusif, berbeda dengan korporat yang dipandang lebih eksklusif. Aspek inklusif akan menimbulkan dukungan sosial yang positif, karena karakter masyarakat sosial Indonesia yang mengagumi keterbukaan. Sampai di sini tentunya dapat diafirmasikan bahwa untuk membangun brand differentiation dibutuhkan CSR. Maka, CSR bukan lagi problematika sosial ironis dari korporasi tetapi menjadi "strategi".

Gambaran inilah yang mewarnai perjalanan Yayasan Dompet Dhuafa dalam membangun brand differentiation. Hal ini dibuktikan dengan pendirian sekolah Smart Ekselensia Republika yang menghasilkan outcomes yang patut dibanggakan. Dompet Dhuafa mampu menemukan potensi-potensi kelas bawah yang jika tidak tersentuh tidak akan sampai pada derajat "membanggakan".

Membangun public trust tentu tidak mudah. Untuk mendapatkan dukungan shareholders dan stakeholders secara maksimal membutuhkan upaya yang tidak singkat. Hingga kini hasil CSR berupa sekolah Smart Ekselensia itu cukup berhasil meluluskan generasi seperti idealisme Indonesia, yakni paralel antara iptek dan imtaq. Berdiri sejak 2004, Smart Ekselensia berusaha menjawab tan-tangan bangsa dengan mengantarkan 90\% anak didiknya ke Perguruan Tinggi Negeri (PTN) favorit di Indonesia. Pada Mei 2019, sekolah ini tengah mewisuda siswa Angkatan ke-11. SMP Smart masuk dalam 25 sekolah terbaik se-Indonesia (Sasongko, 2019).

Fenomena ini sangat menarik perhatian peneliti untuk mengetahui lebih dalam bagaimana proses terbangunnya brand differentiation tersebut. Selain itu CSR yang kini diakui sebagai "strategi" di era marketing 3.0, maka peneliti juga ingin menggali lebih dalam bagaimana strategi CSR tersebut pada akhirnya mampu membangun "strong" brand differentiation Dompet Dhuafa, utamanya melalui terselenggaranya sekolah Smart Ekselensia Republika di Kabupaten Bogor.

Di lain pihak, menurut World Business Council on Sustainable Development (WBCSD) adalah suatu komitmen dari perusahaan untuk melaksanakan etika keperilakuan 
(behavioural ethics) dan berkontribusi terhadap pembangunan ekonomi yang berkelanjutan (sustainable economic development). Komitmen lainnya adalah meningkatkan kualitas hidup karyawan dan keluarganya, komunitas lokal, serta masyarakat luas. Harmonisasi antara perusahaan dengan masyarakat sekitarnya dapat tercapai apabila terdapat komitmen penuh dari top management perusahaan terhadap penerapan CSR sebagai akuntabilitas publik (Effendi, 2016). Manfaat yang diperoleh perusahaan jika mengimplementasikan CSR: 1) Keberadaan perusahaan dapat tumbuh dan berkelanjutan. Selain itu, perusahaan juga mendapatkan citra (image) yang positif dari masyarakat. 2) Perusahaan lebih mudah memperoleh akses terhadap kapital (modal). 3) Perusahaan dapat mempertahankan sumberdaya manusia (human resources) yang berkualitas. 4) Perusahaan dapat meningkatkan pengambilan keputusan pada hal-hal yang kritis (critical decision making) dan mempermudah pengelolaan manajemen resiko (risk management).

Pada saat ini CSR dianggap sebagai investasi masa depan perusahaan. Minat para pemilik modal dalam menanamkan modal di perusahaan yang telah menerapkan CSR lebih besar dibandingkan dengan yang tidak menerapkan CSR. Melalui program CSR dapat dibangun komunikasi yang efektif dan hubungan yang harmonis antara perusahaan dengan masyarakat sekitar (Effendi, 2016).

Adapun dalam implementasinya, terdapat 6 jenis program CSR. Kotler \& Lee (2004) menyebutkan enam kategori aktivitas CSR, yaitu: cause promotions, cause related marketing, corporate societal marketing, corporate philanthropy, community volunteering, dan socially responsible business pratice. Hal ini diperkuat oleh Kartini (2009): 1) Promosi Kegiatan Sosial (Cause Promotions), 2) Pemasaran Terkait Kegiatan Sosial (Cause Related Marketing), 3) Pemasaran Kemasyarakatan Perusahaan (Corporate Societal Marketing), 4) Kegiatan Filantropi Perusahaan (Corporate Philanthropy), 5) Pekerjaan Sosial Kemasyarakatan Sukarela (Community Volunteering), 6) Praktik Bisnis yang Memiliki Tanggung Jawab Sosial (Socially Responsible Practice).

Mengenai branding menurut Bodin \& Odby (2008) elemen yang digunakan dalam pembentukan brand adalah strategi pemasaran positioning dan diferensiasi. Sedangkan Setiarini (2017), meninjau teori strategi segitiga positioning, diferensiasi, dan brand (PDB). Proses pembentukan positioning menciptakan brand identity, mulai dari core identity, extended identity, value proposition, hingga brand essence. Positioning direalisasikan melalui diferensiasi dan kedua aspek tersebut harus terintegrasi. Proses penentuan positioning dapat dilakukan dengan menempuh proses analisis segmentasi dan target market. Segmentation, targeting dan positioning adalah salah satu strategi pemasaran bagian dari elemen pemasaran (Kotler \& Lee, 2004). Analisis pasar merupakan upaya mengelompokkan konsumen potensial dalam kelompok-kelompok pasar khusus yang memiliki kesamaan respon terhadap variabel pemasaran.

Langkah-langkahnya adalah dengan mendefinisikan segmen pasar, menyeleksi basis segmen, bentuk segmen, dan analisis segmen pasar. Setelah itu perusahaan dapat menentukan segmen mana yang akan menjadi sasaran dari produk yang dihasilkan. Proses selanjutnya adalah analisis target pasar. Dalam proses ini perusahaan dibantu untuk mempertimbangkan segmen yang baik untuk dipilih, dikembangkan, dan harus ditinggalkan. Targeting diartikan sebagai proses evaluasi daya tarik segmen dan fokus tawaran yang paling cocok untuk sekelompok orang, wilayah, atau negara yang memiliki respon paling signifikan terhadap produk. Setelah proses penentuan segmen dan target pasar ini dilakukan, maka perusahaan dapat merumuskan posisi paling strategis yang dapat dibentuk bagi produk yang diproduksi. Positioning sendiri merupakan cara yang dilakukan untuk menciptakan faktor pembeda yang unik dalam benak pelanggan (target 
pasar) sehingga terbentuk citra merek atau produk yang lebih unggul dibanding produk pesaing (Hasan, 2013).

Segitiga PDB (Positioning, Diferensiasi, dan Brand) adalah salah satu teori dalam ilmu manajemen pemasaran, hasil turunan dari teori 9 Elemen Pemasaran yang terdiri dari brand, differentiation, positioning, segmentation, targeting, marketing mix, selling, service, dan process (Utami et al., 2020). Widyastuti (2017) mengelompokkan 9 elemen pemasaran ini dalam 3 bagian, strategi, taktik, dan value. Ketiganya merupakan satu kesatuan dengan peran khususnya masing-masing.

Jadi tujuan penelitian ini adalah untuk mengetahui strategi CSR Yayasan Dompet Dhuafa dalam membangun brand differentiation lembaga melalui pendirian sekolah Smart Ekselensia Republika. Ruang lingkup permasalahan dibatasi pada aspek konsep, yakni konsep yang dimaknai peneliti sebagai strategi corporate social responsibility pendirian sekolah "Smart Ekselensia Republika", dikaitkan dengan brand differentiation yang dibangun yayasan Dompet Dhuafa.

\section{METODE}

Jenis penelitian adalah studi kasus yang bersifat deskriptif kualitatif untuk menjabarkan pendirian sekolah disertai penjelasan proses terjadinya, perkembangan dan perubahan-perubahan berbagai aspek dinamika CSRnya. Dengan demikian, terdapat kekhasan kasus yang peneliti jabarkan secara deskriptif berdasarkan kronologi dinamis dan kontekstualnya. Di antara sejumlah strategi CSR Dompet Dhuafa Republika adalah objek penelitian ini. Jadi, strategi CSR untuk pendirian sekolah Smart Ekselensia berbeda dengan praktik usaha lainnya.

Data primer diperoleh berdasarkan hasil wawancara dengan para narasumber yang dipilih berdasarkan seleksi purposive. Adapun data sekunder diambil untuk menunjang data primer yaitu dengan studi pustaka dan dokumentasi. Studi pustaka dengan teori-teori yang relevan dengan strategi dan implementasi kegiatan CSR. Sedangkan dokumentasi yang digunakan adalah berupa, foto-foto kegiatan, laporan kegiatan, data-data yang relevan dengan strategi dan implementasi CSR.

\section{HASIL DAN PEMBAHASAN}

Strategi corporate social responsibility Dompet Dhuafa dalam membangun brand differentiation lembaga, cenderung menggunakan pola-pola sosial sebagai berikut:

\section{Membangun Identitas Lembaga yang Modern - Islami}

Meskipun Dompet Dhuafa mengkhususkan diri dalam corporate culture islami, tetapi pada dasarnya mereka ingin mengilhami dan menginspirasi CSR dalam bentuk charity secara langsung dengan manajemen yang elaboratif, yakni modern - islami. Hal ini mengingat, Indonesia sebagai negara dengan jumlah muslim terbesar, tetapi dampak kesejahteraan bagi umat Islam sendiri masih jauh dari signifikan. Menurut Dompet Dhuafa, korporasi harus memiliki perhatian yang penuh kepedulian, hanya itu harapan strategis.

Dompet Dhuafa menyadari bahwa jumlah perusahaan yang bergerak dalam bidang sosial/nirlaba masih sangat sedikit. Mereka masih menganggap bahwa charity masih menjadi beban pengeluaran. Paradigma ini harus didampingi oleh semangat agama, jika tidak maka pertimbangan biaya akan terus menjadi kendala, padahal dalam kepercayaan agama Islam, bahwa charity atau shodaqoh justru akan memberi efek berlipatnya rejeki. Hal ini yang tidak dimiliki oleh institusi sejenis. Smart Ekselensia tidak saja buah keyakinan itu, tetapi juga melihat charity sebagai komoditas itu sendiri. Komoditas yang tidak dimaknai sebagai bahan jualan tetapi bahan kemuliaan dan 
kemaslahatan bersama. Dompet Dhuafa tidak hanya ingin berkonsep tetapi melakukan sesuatu dalam ikut andil mengurangi beban kemanusiaan, khususnya dalam dunia pendidikan. Mereka percaya bahwa potensi charity itu demikian besar dan memerlukan trust yang tinggi dalam pengelolaannya. Dengan Smart Ekselensia, Dompet Dhuafa ingin menunjukkan bahwa mereka memiliki kemampuan mengelola amanah menjadi berkah bagi umat Islam. Dalam melihat kompetitor, Dompet Dhuafa tentu melihat berbagai fenomena.

Untuk melaksanakan hal itu, tentu Dompet Dhuafa memiliki strategi kolaborasi dengan institusi atau korporasi yang lain. Hal ini disadari bukan hal yang mudah.

Tabel 1. Strategi Kolaborasi Berdasarkan Tipe Korporasi

\begin{tabular}{|c|c|c|}
\hline Tipe Korporasi & Respon & Spektrum Pendekatan \\
\hline Profit Oriented & Menolak & $\begin{array}{l}\text { Zero to charity (Hit and run) } \\
\text { Tidak perlu didekati. }\end{array}$ \\
\hline Tricky & $\begin{array}{l}\text { Menyambut baik tanpa } \\
\text { kepastian }\end{array}$ & $\begin{array}{l}\text { Charity to Philantrohy (Kiss and run) } \\
\text { Dimotivasi pemukanya. }\end{array}$ \\
\hline $\begin{array}{l}\text { Similarity } \\
\text { Platform }\end{array}$ & Menyesuaikan & $\begin{array}{l}\text { Community relations to community development } \\
\text { Dijadikan mitra potensial. }\end{array}$ \\
\hline $\begin{array}{l}\text { Advanced } \\
\text { Spiritualism }\end{array}$ & Mengembangkan & $\begin{array}{l}\text { Community development to social investment } \\
\text { Mitra utama. }\end{array}$ \\
\hline
\end{tabular}

Dari tabel tersebut dapat diketahui bahwa Dompet Dhuafa bukan merupakan lembaga pencari derma, tetapi membangun manajemen CSR yang berkontribusi nyata pada kemaslahatan, dengan membangun trust yang bernawaitu sama. Adapun jika dilihat pendirian Smart Ekselensia, dibandingkan sekolah sejenis yang dibangun atas dasar penghimpunan donator atau korporasi murni, prosesnya menyangkut tahapan: 1) Kesadaran sosial. Dompet Dhuafa mendirikan berbagai pelayanan kaum dhuafa tanpa berangkat dari usaha yang menimbulkan dampak kerugian apapun bagi kalangan manapun. Justru mereka hadir demi kebutuhan yang tidak terakomodasi pihak korporasi atau institusi yang diharapkan. 2) Kesadaran ekonomi. Dompet Dhuafa justru tidak memiliki motif demikian. Mereka tetap percaya bahwa pengelolaan charity akan memberi berkah pada usaha lainnya. Republika memiliki usaha media massa dan Dhompet Dhuafa juga memiliki rumah sakit yang cukup besar. Dompet Dhuafa justru ingin dimiliki masyarakat atau umat. 3) Alasan hukum. Dompet Dhuafa tidak memosisikan diri dalam identitas yang demikian. Identitas brand Dompet Dhuafa sendiri sudah menggambarkan bahwa secara jelas, eksistensi operasionalnya adalah demi kaum dhuafa, jadi pasti mengutamakan CSR secara nyata sepanjang perjalanan usaha.

\section{Membangun Pesan Ekonomi Umat}

Secara historis, Dompet Dhuafa dapat dikatakan sebagai organisasi bisnis, diciptakan sebagai entitas ekonomi yang dirancang untuk menyediakan barang dan jasa kepada anggota masyarakat. Motif laba ditetapkan sebagai insentif utama untuk hasil akhir operasionalnya. Jika melihat Republika, hal ini tentu tidak terpungkiri. Tetapi paradigma Dompet Dhuafa membangun ekonomi umat tidak dirasakan cukup hanya dengan mengandalkan korporasi tetapi penting pula menciptakan kontribusikontribusi lainnya, terutama mendidik SDM yang sesuai harapan masyarakat disertai menciptakan peluang bagi mereka yang menjadi korban dari kompetensi ekonomi. Inilah motif pendirian Smart Ekselensia. 
Perlu disadari bahwa organisasi bisnis merupakan unit ekonomi dasar dalam masyarakat. Dengan demikian, peran utamanya adalah untuk menghasilkan barang dan jasa yang dibutuhkan dan diinginkan konsumen, dan tentunya untuk menghasilkan keuntungan setelah selesainya proses yang dimaksud. Pada titik tertentu, gagasan motif laba diubah menjadi gagasan tentang laba maksimum, dan ini telah menjadi nilai yang bertahan lama. Maka, laba maksimum tentu menjadi tanggung jawab utama karena tanpa pencapaian ini, tanggung jawab yang lain hanya akan menjadi bahan perdebatan saja. Dompet Dhuafa menyadari hal ini, tetapi paradigma Dompet Dhuafa berbeda, karena ada motif spiritualitas islamiahnya. Keuntungan maksimal adalah keuntungan yang diukur kebermanfaatannya dalam membangun SDM sesuai standar dunia dan akhirat. Dengan demikian, orientasi keuntungan maksimal dari Dompet Dhuafa memiliki diferensiasi yang tinggi.

\section{Pengelolalan Pesan Implisit sebagai Pembela Keadilan}

Selain mengejar motif keuntungan, bisnis juga diharapkan mematuhi undangundang dan peraturan yang ditetapkan oleh pemerintah pusat maupun daerah sebagai aturan dasar operasionalisasi bisnis. Hal ini kemudian memunculkan kewajiban pemenuhan perusahaan atas 'kontrak sosial', yang antara lain mencakup positioning bisnis dan masyarakat. Perusahaan diharapkan mampu mengejar misi ekonomi tersebut, tetapi tetap dalam kerangka hukum. Tanggung jawab hukum mencerminkan pandangan 'etika terkodifikasi' dalam arti bahwa mereka mewujudkan gagasan dasar tentang operasional bisnis yang adil. Dasar pemikiran ini juga disadari dan dipahami oleh Dompet Dhuafa. Oleh karena itu segmen usaha Dompet Dhuafa adalah masyarakat dhuafa, yang jika dilihat dari sisi keadilan, merupakan segmen paling tertekan oleh terapan keadilan. Oleh sebab itu, Dompet Dhuafa sama sekali tidak dihadapkan dengan persoalan wacana hukum.

\section{Membangun Tanggung Jawab Etis Intersubjektif}

Meskipun tanggung jawab ekonomi dan hukum mewujudkan norma-norma etika tentang keadilan, namun tanggung jawab etis harus pula mencakup kegiatan dan praktik bisnis yang jauh dari hal-hal yang bertentangan dengan nilai-nilai masyarakat, terutama menyangkut hukum-hukum yang tidak tertulis, terlebih lagi yang tertulis. Tanggung jawab etis ini mewujudkan standar, norma, atau harapan yang mencerminkan kepedulian terhadap apa yang konsumen, karyawan, pemegang saham, dan masyarakat anggap sebagai adil, atau sesuai dengan penghormatan atau perlindungan terhadap hak masing-masing. Dompet Dhuafa dengan Smart Ekselensia justru merasa telah mensinergikan para stakeholders dan shareholders. Norma sama sekali tidak menjadi beban, karena para pemikir justru merasa "berkewajiban" untuk bergabung dalam program Dompet Dhuafa sebagai tanggung jawab moral mereka terhadap permasalahan kemanusiaan.

\section{Mengimplementasikan Filantropis}

Secara teoritis, filantropi mencakup tindakan korporasi sebagai tanggapan atas harapan masyarakat bahwa bisnis harus mewujudkan kondisi warga korporat yang baik. Hal ini termasuk tuntutan terhadap perusahaan agar terlibat aktif dalam tindakan atau program yang mempromosikan kesejahteraan manusia atau setidaknya ada niat baik ke arah itu.

Organisasi bisnis menghasilkan barang dan jasa untuk memenuhi kebutuhan dan keinginan masyarakat dan mendapatkan keuntungan sebagai imbalan atas operasionalnya. Oleh karena itu, karena bisnis sepenuhnya tertanam ke dalam sistem ekonomi, maka komponen pertama tidak hanya terkait dengan bisnis, tetapi juga mempengaruhi seluruh masyarakat. Namun, efek tidak langsung dari tanggung jawab 
ekonomi ini biasanya diabaikan. Pandangan sempit ini membuat keberadaan komponen ekonomi dalam definisi CSR dipertanyakan. Karena kegiatan bisnis yang dimaksudkan (menghasilkan barang dan jasa dengan imbalan keuntungan) dapat dilihat sebagai 'tugas inti' atau 'alasan keberadaan' untuk bisnis, daripada 'tanggung jawab'. Dalam hal ini Dompet Dhuafa justru sanggup menyeimbangkan keduanya. Sebagai organisasi yang basis utamanya adalah bisnis sebagai sebuah keniscayaan, tetapi CSR sebagai tanggung jawab dapat dibuktikan kausalitasnya. Afirmasi bahwa bisnis untuk kemaslahatan dan dengan kemaslahatan akan menciptakan berkah bagi bisnis dapat dijelaskan dalam paradigma bisnis pula. Hal inilah yang kemudian menginspirasi banyak pihak bahwa aksi filantropis dalam bisnis bukan sebuah beban pengeluaran.

\section{Membangun Etika Bisnis}

Jika dilihat dari sumber utama dari pendirian Smart Ekselensia adalah Republika, maka Dompet Dhuafa berangkat dari etika bisnis. Etika pertama menyatakan bahwa etika adalah bersifat personal, kebebasan individu bukan sesuatu yang bersifat umum dan tidak untuk diperdebatkan. Etika ini mengacu pada sifat personal atau keyakinan agama, dan ini adalah suatu pilihan apakah yang dikatakan baik dan apa yang dikatakan buruk. Dalam hal ini Dompet Dhuafa terbuka terhadap kritik dan supervisi atas nama pribadi terhadap operasional usaha yang dibangunnya.

Etika kedua menyatakan bahwa bisnis dan etika jangan disatukan atau dicampuradukkan. Dalam mitos ini dikatakan bahwa bisnis berada pada pasar bebas. Mitos ini didasari pada pemikiran logika dan sama sekali tidak terkait dengan masalah agama atau bahkan etika dan prinsip-prinsip dasar. Bagi Dompet Dhuafa, bisnis justru harus dikaitkan dengan etika kemanusiaan dan ketuhanan.

Etika ketiga menyatakan bahwa etika dalam bisnis adalah berhubungan. Mitos ini adalah salah satu dari mitos yang paling populer, dan ini dipegang sebagai strategi, bahwa tidak ada cara yang diyakini benar atau salah. Benar atau salah tergantung dari kacamata dari yang menyatakan atau terlibat. Bagi dompet Dhuafa, usaha apapun tidak seharusnya menimbulkan dampak bagi rekanan atau kompetitor. Dengan segmentasi dhuafa, maka pilihan ini tidak akan menimbulkan justifikasi salah, karena segmentasi dhuafa tidak akan dapat dikatakan buruk beradasarkan kaca mata agama. Paradigma ini menciptakan kepercayaan diri, bahwa resiko kebangkrutan sangat kecil, karena diferensiasi yang sama sekali tidak mengandung kompetisi. Sangat kecil kemungkinan kompetisi usaha memperebutkan segmentasi dhuafa.

Etika keempat menyatakan bahwa bisnis yang baik berarti mempunyai etika yang baik. Alasan dari pernyataan ini bahwa, sebuah perusahaan akan selalu menjaga kesan sebagai sebuah perusahaan yang baik, menerapkan keadilan dan mempunyai perjanjian kerja sama yang baik dengan pelanggan maupun dengan karyawan untuk mendapatkan keuntungan yang terlegimitasi legal sehingga secara tidak langsung sebuah perusahaan yang bekerja dengan baik otomatis mempunyai etika yang baik. Etika ini dijadikan dasar bagi Dompet Dhuafa dalam memilih bidang CSR. Usaha apapun yang mendukung terciptanya SDM yang baik, proses pendidikan yang baik dengan pencarian bibit unggul terbaik diyakini sebagai usaha yang baik. Dari sinilah gagasan Smart Ekselensia lahir.

\section{Membangun SDM Berkarakter}

Berdasarkan hasil penelitian, hakikat CSR harus dilekatkan dalam konteks untuk mencapai pembangunan berkelanjutan atau sustainable business. Brand tidak lagi harus dipahami sebagai identitas saja, tetapi sebagai reputasi kontributif nyata pada pembangunan sumberdaya manusia. Artinya, CSR harus dilihat sebagai suatu 
komitmen berkelanjutan dari dunia bisnis untuk bertanggung jawab secara ekonomi, sosial dan ekologis mencegah dampak-dampak negatif yang mungkin timbul dan untuk meningkatkan kualitas masyarakat sekitar (termasuk karyawan, pemasok, dan pelanggan) serta lingkungan yang menjadi pemangku kepentingan atau stakeholders.

Dengan demikian, differentiation dalam konteks ini bukan semata "berbeda", tetapi sebuah pilihan yang cenderung minor dan tidak popular dalam dunia bisnis atau target utama dari sebuah korporasi. Jika dunia bisnis yang baik dituntut untuk menyelaraskan pencapaian kinerja ekonomi (profit) dengan kinerja sosial (people) dan kinerja lingkungan (planet) yang sering disebut sebagai tripple bottom-line perfomance, tetapi differentiation merupakan bisnis yang menghadirkan eksistensi Tuhan di dalamnya. Dampaknya tentu akan sangat berbeda jika sebaliknya. Pencapaian itu pada akhirnya akan menempatkan korporasi menjadi corporate citizen dan meraup keuntungan yang langgeng. Hal ini akan mempengaruhi kinerja sosial dan lingkungan dalam manajemen umum. Values yang ditawarkan tidak hanya pencapaian sekuler tetapi kepedulian terhadap benefit yang akan didapatkan di alam akhirat. Efek diferensiasi ini tentunya harus dijadikan dasar, untuk terus dikembangkan dalam CSR dalam target strategi apapun.

Jika ada wacana dalam periklanan bahwa brand without character is nothing, dalam konteks ini brand without differentiation character is nothing. Untuk mencapai itu, strategi CSR menjadi sangat penting. Differentiation character merupakan pencapaian yang memadukan konteks bisnis yang menciptakan nilai bersama dalam tiga kecerdasan sekaligus, yakni kecerdasan intelektual, kecerdasan emosional dan kecerdasan spiritual. Inilah yang mendasari Dompet Dhuafa dengan eksistensi Smart Ekselensia. Kecerdasan intelektual dibuktikan dalam penyelenggaraan pendidikan, kecerdasan emosional dengan membangun usaha layanan sosial kaum dhuafa, serta kecerdasan spiritual dengan prinsip amanah, ibadah dan islamiah.

Sebagai temuan, strategi CSR yang sudah diimplementasikan Dompet Dhuafa merupakan strategi komunikasi CSR yang bersifat terbuka/transparan. Berdasarkan penelitian berjudul "Komunikasi Corporate Social Responsibility pada Official Website Perusahaan Badan Usaha Milik Negara" (Nurjannah dkk., 2017), hasil penelitian menunjukkan bahwa perusahaan BUMN belum sepenuhnya menerapkan transparansi pesan komunikasi CSR pada official website perusahaan. Hal ini berbeda dengan Dompet Dhuafa yang melaporkan secara terbuka dalam release tertentu.

Selanjutnya sebagaimana konsep peningkatan kualitas hidup manusia secara umum, strategi CSR Dompet Dhuafa juga menganut prinsip sustainable development. Prinsip ini sangat penting, sebagaimana diungkapkan Rachmawati et al. (2015) dalam penelitian "Implementasi Program Corporate Social Responsibility di PT. Intiland Development". Penelitian ini dilakukan untuk mengetahui apakah program CSR yang dilaksanakan oleh PT. Intiland Development menjalankan prinsip sustainable development. Artinya strategi CSR sangat tidak etis jika diselenggarakan atas dasar brand differentiation semata, sehingga hanya bersifat temporal. Dompet Dhuafa justru menginginkan brand differentiation lembaga didasarkan atas akuntabilitas yang sustainable.

\section{KESIMPULAN}

Berdasarkan hasil dan pembahasan, dapat dietimologiskan bahwa strategi brand dari Dompet Dhuafa termasuk "Strategi Merek Bersama (Co-Branding Strategy)". Biasanya strategi ini ditempuh oleh perusahaan besar yang sudah memiliki merek yang terkenal dan sudah sangat kuat, sehingga penggunaan dua merek tersebut akan semakin menguatkan 
posisi produk di pasar. Hal ini berarti merek bersama atau co-branding adalah penggunaan dua merek untuk satu produk, atau biasa disebut juga kerjasama branding, dan strategi ini ditempuh untuk mendapatkan kekuatan dari masing-masing merek tersebut. Tampak unifikasi dari Republika dan Dompet Dhuafa yang sudah masyhur dengan aksi CSRnya akan memiliki positioning yang sangat strategis di mata publik.

Model strategi yang digunakan adalah BPD (Branding, Positioning dan Differentiation). Tahap branding dilampaui dengan membangun identitas lembaga yang modern - islami, membangun pesan ekonomi umat dan pengelolalan pesan implisit sebagai pembela keadilan. Tahapan positioning, dilakukan dengan membangun tanggung jawab etis intersubjektif serta implementasi filantropis. Sedangkan tahapan differentiation terlaksana dengan membangun etika bisnis yang masih belum populer serta membangun SDM berkarakter pejuang yang berkeprihatinan.

Dengan demikian, strategi CSR Yayasan Dompet Dhuafa dalam membangun brand differentiation didasari oleh kesadaran sosial, bahwa kontribusi bisnis adalah kemaslahatan sosial. Selanjutnya ada kesadaran ekonomi, bahwa keuntungan maksimal bisnis adalah keuntungan maksimal dalam meningkatkan charity pada masyarakat. Keberkahan bisnis akan lahir dari ikatan emosional masyarakat yang merasa ikut memiliki. Yang terakhir adalah adanya kesadaran hukum. Bahwa usaha keadilan yang dijadikan kritik publik pada korporasi bagi Dompet Dhuafa tidak akan terjadi manakala usaha yang dilakukan memiliki segmen dhuafa. Dengan strategi ini, Dompet Dhuafa tidak akan banyak berhadapan dengan konflik sehingga misi utama kemaslahatan umat atau sesama dapat dijalankan secara sustainable.

Differentiation merupakan pencapaian yang memadukan konteks bisnis nilai bersama dalam tiga kecerdasan. Kecerdasan intelektual dibuktikan dalam penyelenggaraan pendidikan, kecerdasan emosional dengan membangun usaha layanan sosial kaum dhuafa, serta kecerdasan spiritual dengan prinsip amanah, ibadah dan islamiah. Jadi diferensiasi bisnis Dompet Dhuafa merupakan bisnis yang menghadirkan Tuhan dalam operasionalnya.

\section{UCAPAN TERIMA KASIH}

Peneliti ucapkan terima kasih yang sebesar-besarnya kepada Direktorat Riset dan Pengabdian Kepada Masyarakat Direktorat Jenderal Penguatan Riset dan Pengembangan Kementerian Riset, Teknologi dan Perguruan Tinggi Republik Indonesia yang telah sepenuhnya mendanai dan memfasilitasi penelitian ini.

\section{DAFTAR RUJUKAN}

Adiyanto, Y., \& Sunaryo, D. (2017). Pengaruh Customer Orientation Dan Competitive Orientation Terhadap Customer Satisfaction Melalui Salesperson Customer Orientation. Jurnal Sains Manajemen, 3(1), 15-40. https://doi.org/10.30656/sm.v3i1.291

Aryawan, M., Rahyuda, I. K., \& Ekawati, N. W. (2017). Pengaruh Faktor Corporate Social Responsibility (Aspek Sosial, Ekonomi, dan Lingkungan) Terhadap Citra Perusahaan. E-Jurnal Manajemen Unud, 6(2), 604-633. https://ojs.unud.ac.id/index.php/Manajemen/article/view/25821

Bodin, J., \& Odby, J. (2008). Positioning and Brand Personality within Research Charity Organization. Lulea University of Technology.

Dewi, S. C., Ali, M., \& Prakoso, B. (2020). Rekonstruksi Pasal 74 Undang-Undang Nomor 40 Tahun 2007 Tentang Tanggung Jawab Sosial Perseroan Terbatas Terkait Kewirausahaan Sosial. Jurnal Ilmu Kenotariatan, 1(1), 77-92. https://doi.org/10.19184/jik.v1i1.18236 
Effendi, M. A. (2016). The Power Of Good Corporate Governance: Teori Dan Implementasi (2nd ed.). Salemba Empat.

Erawaty, A. . E. (2009). Persoalan Hukum Seputar Tanggung Jawab Sosial dan Lingkungan Perseroan dalam Perundang-Undangan Ekonomi Indonesia. Jurnal Legislasi Indonesia, 6(2), 87-106. https://ejurnal.peraturan.go.id/index.php/jli/article/view/322

Hasan, A. (2013). Marketing dan Kasus-Kasus Pilihan (T. Admojo (ed.)). Center for Academic Publishing Service.

Kartini, D. (2009). Corporate social responsibility: transformasi konsep sustainability management dan implementasi di Indonesia. Refika Aditama.

Kotler, P., \& Lee, N. (2004). Corporate Social Responsibility: Doing the Most Good for Your Company and Your Cause (1st ed.). Wiley Online Library.

Nayenggita, G. B., Raharjo, S. T., \& Resnawaty, R. (2019). Praktik Corporate Social Responsibility (CSR) Di Indonesia. Focus: Jurnal Pekerjaan Sosial, 2(1), 61-66. https://doi.org/10.24198/focus.v2i1.23119

Rachmawati, S., Zainuddin, M., \& Irfan, M. (2015). Implementasi Program Corporate Social Responsibility di PT. Intiland Development. Prosiding Penelitian Dan Pengabdian Kepada Masyarakat, 3(3), 390-394. https://doi.org/10.24198/jppm.v3i3.13782

Sasongko, A. (2019, May). Smart Ekselensia Wisuda 40 Siswa di Hari Pendidikan Nasional. Republika.Co.Id.

https://republika.co.id/berita/pendidikan/eduaction/pqx3nl313/smartekselensia-wisuda-40-siswa-di-hari-pendidikan-nasional

Setiarini, A. T. (2017). Strategi Positioning Dan Diferensiasi Dalam Upaya Membangun Brand, Studi Kasus Ngayogjazz. Jurnal Tata Kelola Seni, 1(2), 54-67. https://doi.org/10.24821/jtks.v1i2.1641

Suharto, E. (2010). Membangun Masyarakat Memberdayakan Rakyat Kajian Strategis Pembangunan Kesejahteraan Sosial dan Pekerjaan Sosial. PT Refika Aditama.

Utami, H., Prasetya, B., Salsiyah, S. M., Sadriatwati, S. E., \& Devie, E. (2020). Developing Creative Business Brands for Entrepreneurial Students through Differentiation and Positioning Strategies. Jurnal Admisi Dan Bisnis, 20(3), 181-192. https://doi.org/10.32497/ab.v20i3.1766

Widyastuti, S. (2017). Manajemen Komunikasi Pemasaran Terpadu: Solusi Menembus Hati Pelanggan (I. Hadi (ed.)). FEB-UP Press. 